\title{
Work situation operative model MOST: linking diagnosis and intervention to improve work conditions
}

\author{
Karen Lange Morales ${ }^{\mathrm{a}, \mathrm{b}, \mathrm{c}}{ }^{*}$, Gabriel García-Acosta ${ }^{\mathrm{a}, \mathrm{d}}$, William Urueña-Téllez ${ }^{\mathrm{e}}$ and Adriana Pérez ${ }^{\mathrm{f}}$ \\ ${ }^{a}$ MIMAPRO Research Group - School of Industrial Design, Universidad Nacional de Colombia, Ciudad \\ Universitaria, Edif. 303 - Of 316, Bogotá, Colombia \\ ${ }^{\mathrm{b}}$ Ergofactos Ltda, Carrera 53 146-10, Bogotá, Colombia \\ 'Institute of Ergonomics, Darmstadt University of Technology, Petersenstrasse 30, D-64287, Darmstadt, Germany \\ ${ }^{\mathrm{d}}$ Centre de Disseny d'Equips Industrials, Universitat Politècnica de Catalunya, C. Llorens Artigas, 4, planta 0, \\ edifici U, Parc Tecnologic de Barcelona, 08028, Barcelona, Spain \\ ${ }^{e}$ Pontificia Universidad Católica del Ecuador, Av. 12 de Octubre 1076 y Av. Patria, Quito, Ecuador \\ ${ }^{\mathrm{f}}$ Triatecsa, Av. Simón Bolivar S/N barrio Perla Quiteña - La Huerta, Quito, Ecuador
}

\begin{abstract}
This paper presents the model "Work Situation Operative Model" - MOST (after its Spanish acronym). It offers a comprehensive, systemic approach to analysing work stations and/or work processes, serving also as a framework for pursuing various ergonomic and occupational health and safety goals. Originally produced for a food sector company, the model has been extended and successfully applied in several industries in Colombia and Ecuador, including cement, oil, and paper industries. Based on a systemic understanding of work systems and tasks, the model not only allows different, commonly-used methods and tools for evaluating or assessing the risk of muscular-sketetal disorders to be included, but also supports occupational risk management strategies. Hence, one of its more important contributions relies on providing meaningful information that is useful for improving the work station and/or work process through design and re-design, by focusing on the interactions between all system elements.
\end{abstract}

Keywords: ergonomic system, ergonomic method, comprehensive model, work place design, work station design

\section{Introduction}

Work station and work process analysis and intervention are core ergonomics practices in the occupational health arena. Many methods and tools have been developed and are currently used. Some of them have been proposed for special working scenarios, while others emphasise their analysis of specific dimensions and variables. However, even if useful for identifying risk factors and allocating body/muscle strain and fatigue, these approaches do not necessarily provide useful information for resolving the situation - i.e. developing design proposals aimed at overcoming the analysed problems. In other words, knowing "what is happening" does not necessarily contribute to knowing "what to do".

MOST was developed by Ergofactos Ltd. to meet the demand of a Colombian food sector company, and set out to go beyond the diagnosis and prioritisation of problems. The goal was to link diagnosis with control phases, supporting the whole optimisation process.

It provides a kind of map that allows occupational health practitioners and related stakeholders to have a detailed understanding of the characteristics, limits and interactions of all elements in a work system. This is especially important when improvements are being implemented, because designers need to establish clear requirements. Therefore, it is important not

\footnotetext{
*Corresponding author. E-mail: klangem@unal.edu.co.
} 
only to investigate and take into account human factors, but also to consider other aspects, such as industrial and environmental matters. This justifies the creation of models that allow system requirements to be established from a comprehensive viewpoint, looking at tasks and their components, immersed in an environment.

\section{Development of the model}

\subsection{Some theoretical elements}

Two theoretical and practical ergonomic streams underlie this model. One the one hand, the ergonomic system proposed by García-Acosta [1] was taken as the core concept for achieving a systemic understanding of the work station and work process; on the other hand, concepts related to Activity Theory, such as formal task, redefined task and updated task [2], were used for analysing and understanding the differences frequently found between what a worker is expected to do (formalisation of a task), and the real performance of it by the worker. Hence, two complementary approaches are combined. Firstly, the systemic approach allows part and the whole of a work system to be visualised, thereby boosting the understanding of interactions between the multiple elements that make up the system. Secondly, the Activity Theory approach recognises that humans are more than just another element in the system, enabling differences between what is institutionally and organisationally pretended, and the way workers act and solve concrete work situations, to be understood.

It is important to mention that this model is oriented toward industrial design, and conceived as a creative activity with the goal of establishing multifaceted qualities of objects, processes, services, and systems throughout their whole product life cycles [3].

\subsection{Description of the model}

The basic principles of the model are the following:

- Systemic understanding of the work station and work process through an analysis of the ergonomic system - i.e. human being, objectsmachines, physical space, and resulting interactions, considering relationships with the work organisation and/or technological variables [4];
- Sensitivity to identifying the differences between the formal task and the real task performed by the worker;

- Flexibility, for incorporating specific tools according to the requirements and needs of the particular company; and

- Capacity to detect technological state and prospective technological changes.

\subsection{Specific instruments}

The model includes specific instruments for capturing data relating to all ergonomic system elements, and instruments for deducing interactions between elements. The instruments are organised in two groups. The first group records the task, as a system and as an action, including a characterisation of the interacting elements, and its application is obligatory. The second group concentrates on interactions between the different elements. The first set of instruments must be applied, while some of the specific tools in the second group may vary, depending on the specific interest of the company and the type of work being observed. Most of the instruments in this group are validated and well-known tools that are already incorporated into many occupational health risk management systems.

The first group of instruments includes the following items:

- Description of the task as a system: it allows the task to be located as the result of the interactions in the system. Hence, the formal task is registered (what the worker has to do, according to the supervisor or written procedures), along with the re-defined task (what the worker interprets, the activity itself, how he/she performs the task) and the up-dated task (changes or adjustments made by the worker, depending on unexpected situations, in order to make it possible to continue performing the task). Here is also registered data regarding work organisation (shifts, pauses, shift rotation, and dependency relationships)

- Data regarding human beings: this instrument captures anthropometric data, important findings relating to the medical history, education and qualification of workers holding this post, working rules (simultaneous, parallel, successive), and data regarding type of contract, seniority)

- Data about physical space: includes workstation layout, interferences between workstations, performing areas. Functional relationships with 
other workstations or work processes are registered, including communication channels. Safety issues (emergency exits, demarcation of areas, signs, location of emergency equipment) and environmental aspects like thermal, sound, lighting, biological air quality, and vibration conditions are taken into account.

- Object / machine data: With this tool, all objects that play a role during the work process are classified, including endowment equipment and personal protection devices. The instrument allows not only technological level and technological state to be recorded, but also potential interaction modes (maintenance, supervision, regulation, operation, cleaning). A general characterisation of elements is also done, considering dimensions, apparent problems, and intervention possibilities.

The second group of instruments is headed by a format where action principles involved in the different interactions are registered, taking into account postures, segment positions, comfort angles, work cycles, strength requirements and movements requirements. In other words, this tool deals with biomechanical aspects resulting from the interaction between human being and the objects involved when the activity is being performed. In addition to this tool, at least two established methods for assessing physical load are performed, such as Sue Rodgers method [5], Corporal Mapping [6], OWAS [7], and Job Strain Index [8].

Complementary to the previous instruments, videos are sometimes captured in order to enhance information that is available during the analysis and design process.

\subsection{Application of model}

The model's main purpose, parallel to establishing a diagnosis, is to build a basis for further workstation optimisation of health and productivity conditions, so that requirements for the design or re-design of technologies, techniques and forms of organisation can be driven. MOST has been applied to:

- performing a comprehensive analysis of work station and work process conditions;

- establishing design requirements, and testing and evaluation criteria for measuring intervention effectiveness;

- supporting occupational health and safety management, in order to identify irregularities and areas where there is room for improvement; and
- as a guide for experts' intervention as part of participative occupational health and safety strategies like SOBANE [9].

This model highlights the importance of a comprehensive view, emphasising the context and the organisational particularities of the company, in line with situated ergonomics.

\section{Discussion and future work}

Based on the experience of applying MOST in different scenarios, the following advantages can be outlined:

- the possibility of including methods for different purposes, according to companies' requirements;

- it makes the establishment of design requirements and intervention strategies easy, including evaluating criteria;

- it can be integrated with ongoing health and safety management systems; it is compatible with participatory processes;

- the model is easily understood by health and safety, production, and management stakeholders inside the companies;

- and finally, thanks to its systemic approach, MOST makes it possible to include connections between different work stations or work processes, thereby enhancing the possibilities of detecting related problems.

Application in the Colombian industrial and production context, in contrast to the Ecuadorian context, has resulted in it being appreciated that the model has a basic structure that can be replicated, yet is flexible at the same time, thereby allowing expert ergonomists to navigate without necessarily having to adhere strictly to a package of unalterable formats. Quite the contrary, for when the applications were being applied both in Colombia and in Ecuador, it was found that flexibility is not a synonym for lack of control or strictness, and we therefore insist that the model is more like a navigational chart showing "labour routes" (processes and their work conditions) than a "straitjacket"

According to the SOBANE strategy, MOST belongs to the general prevention strategy from the second level - in other words, "subsequent intervention factors, where aspects of the problem will be studied in depth with a view to [...] finding the most effective solutions" [9]. 


\section{References}

[1] García-Acosta, G. 2002. La ergonomía desde la vision sistémica. Unibiblos; Bogotá.

[2] Fiahlo, F., Santos, N., 1997. Manual de análise ergonomica no trabalho. Genesis Editora, Curitiba.

[3] International Council of Societies of Industrial Design, 2000 $\begin{array}{llll}\text { Accessed on: } & \text { Feb } 2011 .\end{array}$ http://www.icsid.org/about/about/articles31.htm

[4] García-Acosta, G. and Lange Morales, K. 2008. Macroergonomic study of food sector company distribution centres. Appl. Ergon. 39, 439-449.

[5] Rodgers, S., (1992). Functional job evaluation technique in Ergonomics. Occupational Medicine: State of the Art Reviews. Vol 7, pp. 679-711
[6] Karwoski, W., Marras, W.S. 2003. Body discomfort assesment tools. In: Occupational Ergonomics: Engineering and administrative controls. CRC Press: Boca Raton.

[7] Karhu, O; Kansi, P.; Kourinka, I. 1977. Correcting working postures in industry: A practical method. Appl. Ergon. 8 (4) 199-201.

[8] Moore, J.S.; Garg, A., 1995. The Strain Index: A proposed method to analyze jobs for risk of distal upper extremity disorders. American Industrial Hygiene Association Journal, 56, pp 443-458.

[9] Malchaire, J.B. The Sobone risk management strategy and the Déparis method for the participatory screening of the risks. Int. Archives of Occup. and Environ. Health. 77, (6) 443-450. 